\title{
Induction of Anti-Myelin Antibodies in EAE and Their Possible Role in Demyelination
}

\author{
R.H. Sadler, M.A. Sommer, L.S. Forno, and M.E. Smith \\ Departments of Neurology (R.H.S., M.A.S., M.E.S.) and Pathology (L.S.F.), Stanford University Medical \\ Center, Stanford, and Veterans Affairs Medical Center, Palo Alto, California
}

Experimental allergic encephalomyelitis is characterized by invasion of lymphocytes and macrophages into the central nervous system resulting in inflammation, edema, and demyelination. Sera from Lewis rats from 7-95 days after immunization with purified guinea pig CNS myelin were examined with respect to their ability to opsonize myelin. This was correlated with the appearance of antibody components and the relative amounts of antibody to myelin basic protein (MBP) and proteolipid protein (PLP). Sera from rats 10-95 days after immunization preincubated with purified myelin induced phagocytosis of myelin by cultured macrophages with the resulting production of cholesterol ester. This opsonization activity as measured by the percentage of cholesterol esterified reached a peak at 26-27 days after immunization but remained significantly elevated up to 95 days postimmunization compared to the activity of serum from the Freund's adjuvant-injected controls. Immunoblots of the sera revealed a gradual increase in antibody activity against myelin components. ELISA assays for MBP and PLP antibody showed a similar pattern. Antibody to galactocerebroside (GC) was not detected by immunostains nor by the ELISA assay. Areas of demyelination were observed histologically by luxol-fast blue stained spinal cords up to 60 days post-immunization. These results indicate that antibodies to myelin protein when given access to myelin through or within the blood brain barrier could initiate or enhance the phagocytic response by peripheral or resident macrophages.

Key words: macrophages, demyelination, EAE, antibody, myelin, opsonization

\section{INTRODUCTION}

Experimental allergic encephalomyelitis (EAE) is an autoimmune disease characterized by the invasion of lymphocytes and macrophages into the central nervous system. Myelin is destroyed by phagocytic cells which strip off the myelin lamellae, and ingest and digest the myelin components (Lampert, 1967). Invading periph- eral macrophages and resident microglia have been implicated as agents of myelin destruction, but their relative participation in this process is not clear. In EAE lesions, myelin has been shown to be attached to the macrophage membrane by coated pits, indicating a role for a ligandmyelin complex in phagocytosis (Epstein et al., 1983; Raine, 1984). That anti-myelin antibody may serve as this ligand has been suggested by several groups of investigators. We have previously shown that phagocytosis of myelin in vitro by cultured macrophages is greatly facilitated by the presence of antisera and IgG antibodies to myelin basic protein (MBP) and galactocerebroside (GC) (Trotter et al., 1986; Smith and De Jong, 1987; Smith et al., 1990). Goldenberg et al. (1989) measured uptake of labeled myelin by mouse macrophages and showed elevated opsonic activity by antibodies to myelin, myelin basic protein, and galactocerebroside compared to normal serum IgG. IgG deposition in the myelin sheath has been observed in serum-induced complementdependent demyelination in vitro (Johnson et al., 1974). Subsequently Prineas and Graham (1981) have shown polar capping of $\mathrm{IgG}$ on macrophages in the vicinity of areas of active myelin destruction in multiple sclerosis lesions. Thus the $\mathrm{Fc}$ portion of the anti-myelin antibody linked to the Fc receptors of the macrophages may serve as an effective ligand for myelin uptake via coated pits in both EAE and MS as suggested by Prineas' group.

This study was initiated in order to attempt to correlate the antibody characteristics with myelin destruction. In work reported here we investigated the characteristics of anti-myelin antibody in EAE of the Lewis rat. Although large demyelinated areas are not prominent in EAE in this strain, we were able to see evidence of substantial demyelination both at the time of maximum clinical symptoms and severity of inflammation, as well as later in this disease.

Received April 12, 1991; revised June 7, 1991; accepted June 7, 1991

Address reprint requests to Dr. Marion E. Smith, Department of Neurology 127A, VA Medical Center, 3801 Miranda Avenue, Palo Alto, CA 94304 . 


\section{MATERIALS AND METHODS}

\section{Animals}

Male Lewis rats, about $250 \mathrm{~g}$, were obtained from Charles Rivers (Wilmington, MA). After a week-long quarantine period they were immunized in each inner flank with $0.125 \mathrm{ml}$ Freund's adjuvant emulsion containing $4 \mathrm{mg}$ lyophilized guinea pig myelin and $3 \mathrm{mg}$ H37RA Mycobacterium tuberculosis/ml emulsion (2:1 Freund's incomplete adjuvant/saline). Control rats were immunized with Freund's adjuvant containing only the M. tuberculosis. Blood was collected at designated times from seven up to 95 days after immunization from rats decapitated under Halothane anaesthetic. After 7 days only rats showing or recovering from clinical symptoms of EAE were used for collection of blood. The serum was prepared and pooled, so that each serum sample consisted of pooled serum from two rats treated identically, and then stored at $-70^{\circ}$. Spinal cords were dissected from each animal and fixed in Bouin's solution. After paraffin embedding, $10 \mu \mathrm{m}$ sections were prepared and stained with hematoxylin and eosin, and with Luxol fast blue-cresyl violet for myelin. The sections were examined by light microscopy, and the degree of infiltration of cells and demyelination were noted.

\section{Preparation of IgG}

IgG was prepared from serum aliquots by affinity chromatography using Gamma Bind $\mathrm{G}$ columns (Genex, Gaithersberg, MD) or Protein A/G Agarose (Schleicher and Schuell, Keene, $\mathrm{NH}$ ), according to the instructions of the manufacturers. Considerably less IgG was isolated from the rat serum than from serum of similarly immunized rabbits previously examined.

\section{Macrophage Cultures}

Macrophages were prepared from rats injected 4 days previously with thioglycollate as described elsewhere (Trotter et al., 1986). These were allowed to adhere to $60 \mathrm{~mm}$ plastic tissue culture plates in the presence of 5\% newborn calf serum then after 2 hours the nonadherent cells were washed off. The adherent macrophages were cultured overnight in $\mathrm{N} 2$ medium (Bottenstein and Sato, 1979). Aliquots of $\left[{ }^{14} \mathrm{C}\right]$-acetate-labeled myelin (Trotter et al., 1986) (0.1 mg protein/plate) were preincubated with the various sera or IgGs and added to each culture dish. After $30 \mathrm{hr}$ the cells were scraped off with their medium, lyophilized, and the lipids were extracted, and separated on thin layer chromatography plates. The spots visualized by iodine vapor were scraped into scintillation vials, and counted for radioactivity as previously described (Trotter et al., 1986; Smith et al., 1990). The formation of radioactive cholesterol ester as an indicator of myelin phagocytosis and breakdown by macrophages was assessed.

\section{Preparation of Immunoblots and Immunostaining}

The antibody species contained in the serum were examined after immunoblotting. Purified rat myelin proteins were separated by polyacrylamide gel electrophoresis using $12 \%$ acrylamide and the buffer system of Laemmli (1970). The gels were electroblotted overnight to nitrocellulose membrane (Towbin et al., 1979), and then immunostained using serum from the EAE rats prepared at different time intervals after immunization or from Freund's adjuvant-injected controls (FAC). For GC detection, small strips of nitrocellulose membrane were dipped at one end into an ethanol solution of bovine brain galactocerebroside (mixed hydroxy- and non-hydroxy, Sigma Chemical Co., St. Louis, MO. The blots and strips were exposed to the diluted antisera (1:250 or 1: 500 ) overnight and visualized by the peroxidase-antiperoxidase methods using diaminobenzidine.

\section{ELISA Procedures}

Measurement of comparative antibody levels of the various sera was performed for MBP, proteolipid protein (PLP), and GC. MBP was prepared by acid extraction of denatured protein after chloroform-methanol extraction of purified myelin (Smith, 1976). PLP was kindly provided by Dr. Marjorie B. Lees. For the MBP assay, 96 well plates were coated overnight with myelin basic protein, $10 \mu \mathrm{g} / \mathrm{ml}$ in carbonate buffer, $\mathrm{pH} 9.8$. After rinsing in phosphate-buffered saline (PBS) the plates were blocked with $1 \%$ bovine serum albumin in PBS, for $2 \mathrm{hr}$ at $37^{\circ} \mathrm{C}$. The test sera were diluted from 1:200-256,000 in $1 \%$ bovine serum albumin-PBS and incubated at $37^{\circ} \mathrm{C}$ for $1 \mathrm{hr}$, and then incubated with alkaline phosphatase conjugated to mouse anti-rat IgG, 1:1,000 for $1 \mathrm{hr}$ at $37^{\circ} \mathrm{C}$. After reaction with p-nitrophenylphosphate enzyme substrate $(0.1 \mathrm{mg} / \mathrm{ml}$ in $0.05 \mathrm{M}$ carbonate buffer, $\mathrm{pH}$ 9.8), color was analyzed with a microplate reader (Dynatech, Chantilly, VA). PLP converted to the watersoluble form diluted in triple-distilled water was used to coat the plates $(10 \mu \mathrm{g} / \mathrm{ml})$ which were incubated overnight at $37^{\circ} \mathrm{C}$ according to Macklin and Lees (1982). Antisera were incubated at $37^{\circ} \mathrm{C}$ for $30 \mathrm{~min}$. Enzyme conjugation and quantitation were carried out as with MBP described above. For the galactocerebroside assays the cerebrosides were prepared as described by Ichioka et al. (1988) and diluted to $10 \mu \mathrm{g} / \mathrm{ml}$ in $50 \%$ ethanol. Plates were coated with $100 \mu \mathrm{g} /$ well lipid solution and incubated at $25^{\circ} \mathrm{C}$ for $2 \mathrm{hr}$. Antisera were incubated at $37^{\circ} \mathrm{C}$ for $1 \mathrm{hr}$, and then with alkaline phosphatase as described above. 


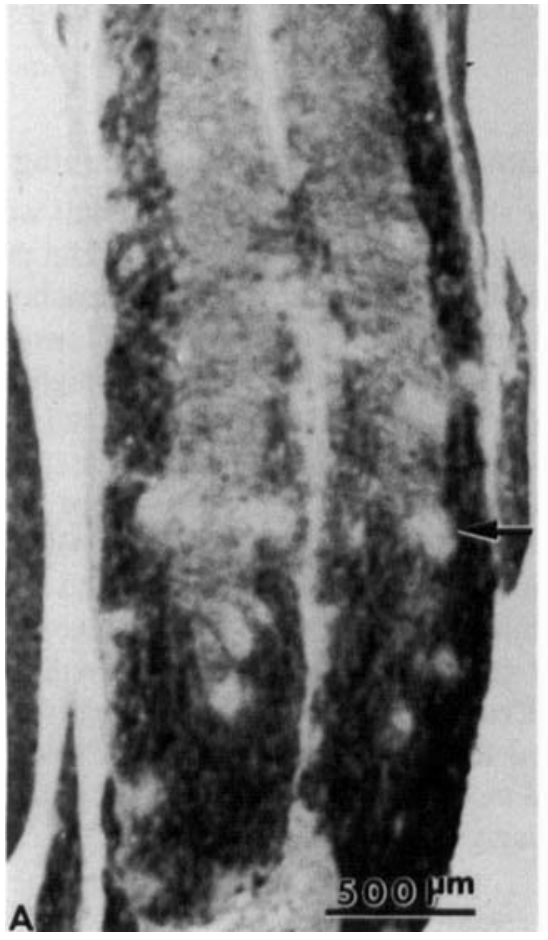

Fig. 1. Lumbar spinal cord 10 days post-immunization stained with luxol-fast blue-cresyl violet. A: Numerous focal areas of demyelination (arrow on example) surrounding blood vessels. B: Higher magnification of area marked by arrow. Marked loss

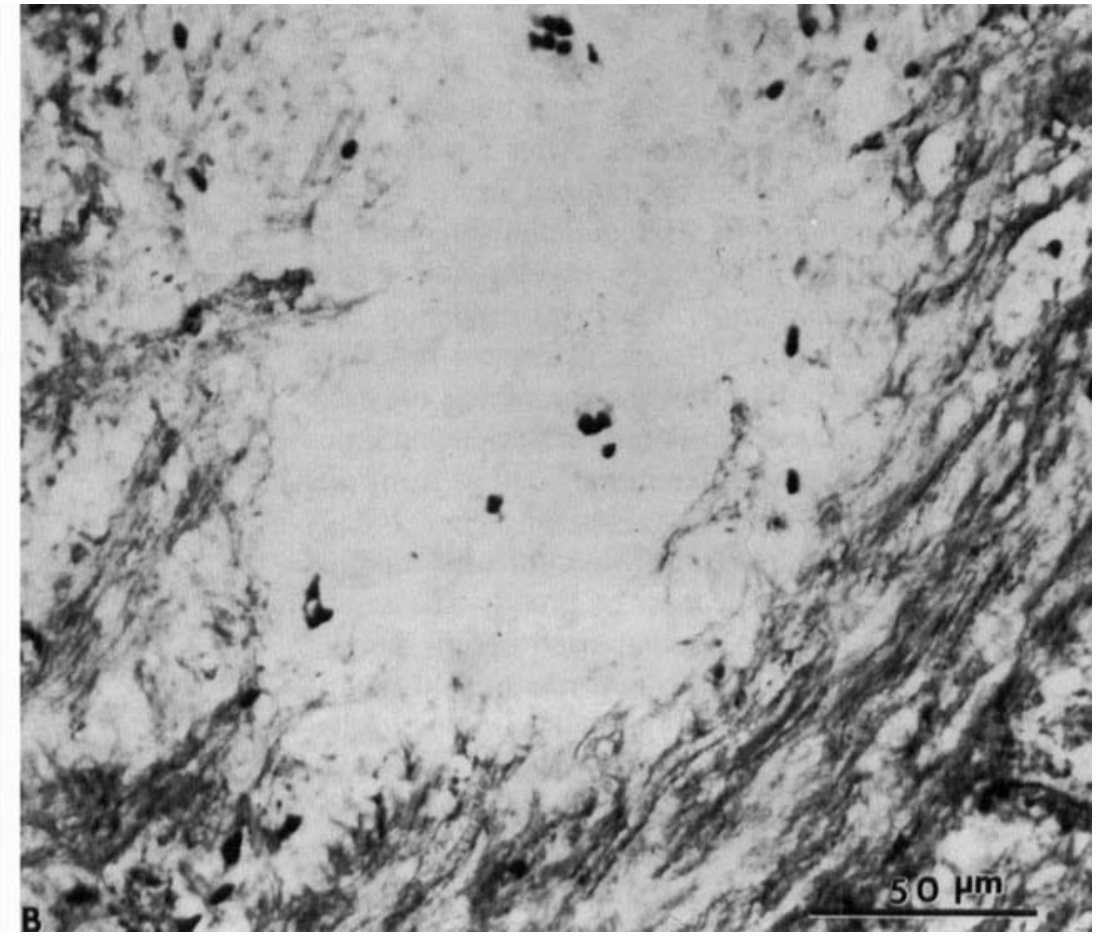

of myelinated fibers in lesion. Cells within the lesion included many macrophages; those on the margin of the lesion appeared to contain myelin remnants. Few astrocytic fibers were visible by immunostaining for GFAP.

\section{RESULTS}

\section{Animals}

At 9-10 days after immunization the rats showed a sudden loss of weight and developed a slight tremor. Between 10-12 days weight loss continued, and the animals became paralyzed in the hind legs. Some animals suffered complete paralysis. Although some deaths occurred, most regained their ability to walk by day $15-16$, but the weight loss was not reversed until day $18-20$. The animals remained thin, some with a continued tremor until about 1 month after immunization. Control weight was not regained until 50-60 days.

\section{Histology}

Examination of histological sections of spinal cords stained by conventional hematox ylin and eosin methods revealed infiltration of inflammatory cells, especially in the meninges, as early as seven days after immunization in some animals. By 9 days all animals showed large numbers of focal lesions. Inflammatory lesions were particularly severe at 10-14 days and then gradually decreased in number, although lesions, some of which were rather large, could be seen as late as 60 days after immunization. As late as 61 days postimmunization, fo- cal perivascular lesions resembling early lesions were present. Although lesions were seen most frequently in the lumbar spinal cord, the thoracic and cervical areas also contained many areas of inflammation. Many large lesions were accompanied by demyelination, as visualized by luxol-fast blue-cresyl violet stains. These were seen as early as 10 days postimmunization when many areas of demyelination were seen surrounding the microvessels (Fig. 1A,B). With time, these gradually decreased in number, but demyelinated areas persisted up to 60 days, the latest time of tissue examination (Fig. 2A,B for day 35). The demyelinated areas contained numerous mononuclear cells including phagocytic cells, and, especially at later times, hypertrophied astrocytes with proliferated fibers were revealed by immunostaining with GFAP antiserum (not shown).

\section{Effect of Sera on Myelin Phagocytosis}

The amount of radioactive cholesterol ester formed from myelin-EAE serum complexes incubated for $30 \mathrm{hr}$ with cultured macrophages was compared with that from myelin preincubated with FAC serum or from myelin alone. The amount of radioactive cholesterol esterified was assessed as a measure of the amount of myelin- 


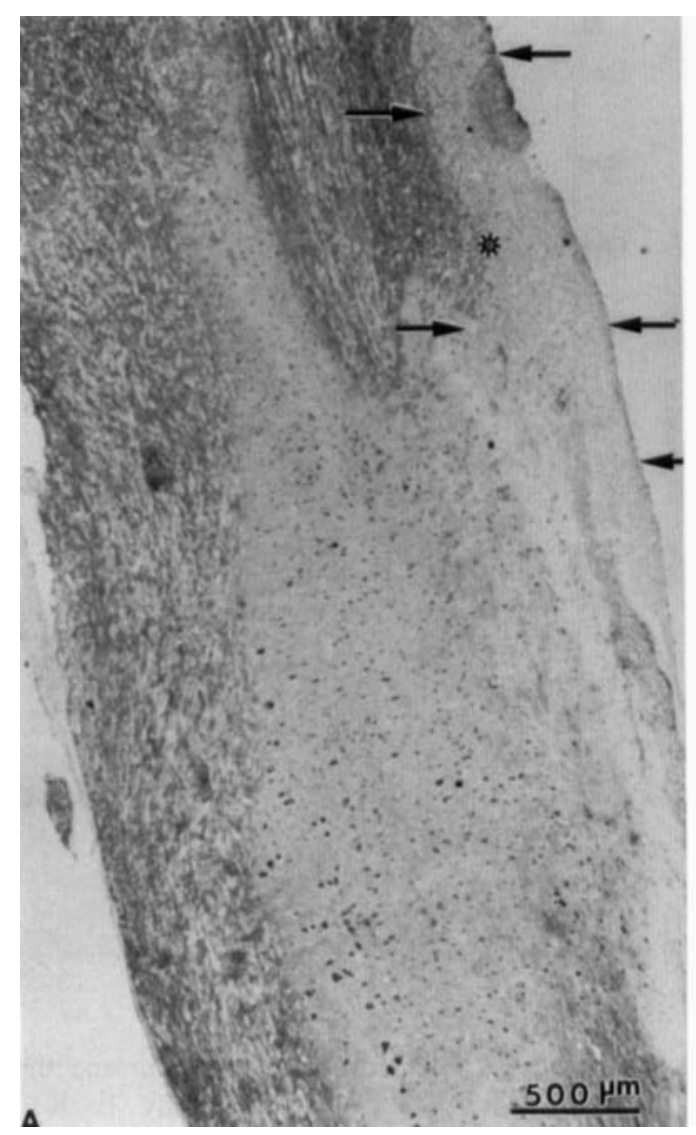

Fig. 2. Lumbar spinal cord 35 days post-immunization stained with luxol-fast blue-cresyl violet. A: A single large subpial demyelinated area (arrows). B: Higher magnification of area

phagocytized and degraded. Radioactive cholesterol ester increased linearly over the $30 \mathrm{hr}$ incubation time with the largest amount formed from myelin preincubated with EAE serum (Fig. 3A). About $40 \%$ of this amount of cholesterol ester was formed from myelin preincubated with FAC serum, and about $20 \%$ from untreated myelin. The relative amounts of radioactive triglyceride produced showed approximately the same relationships, although the rate of production was not quite linear (Fig. 3B).

In similar experiments radioactive cholesterol ester was measured using for opsonization a large series of sera collected from EAE animals 7-95 days after immunization. Each serum sample was a pool from two rats. With 7 day serum the amount of cholesterol esterified in $30 \mathrm{hr}$ was not significantly different from that of myelin opsonized with FAC serum (13.8\% of cholesterol esterified) (Fig. 4). Thereafter, cholesterol esterification increased rapidly with time after immunization with serum from animals 12 days post-immunization, promoting cholesterol esterification up to $24.7 \%$ of the total. With

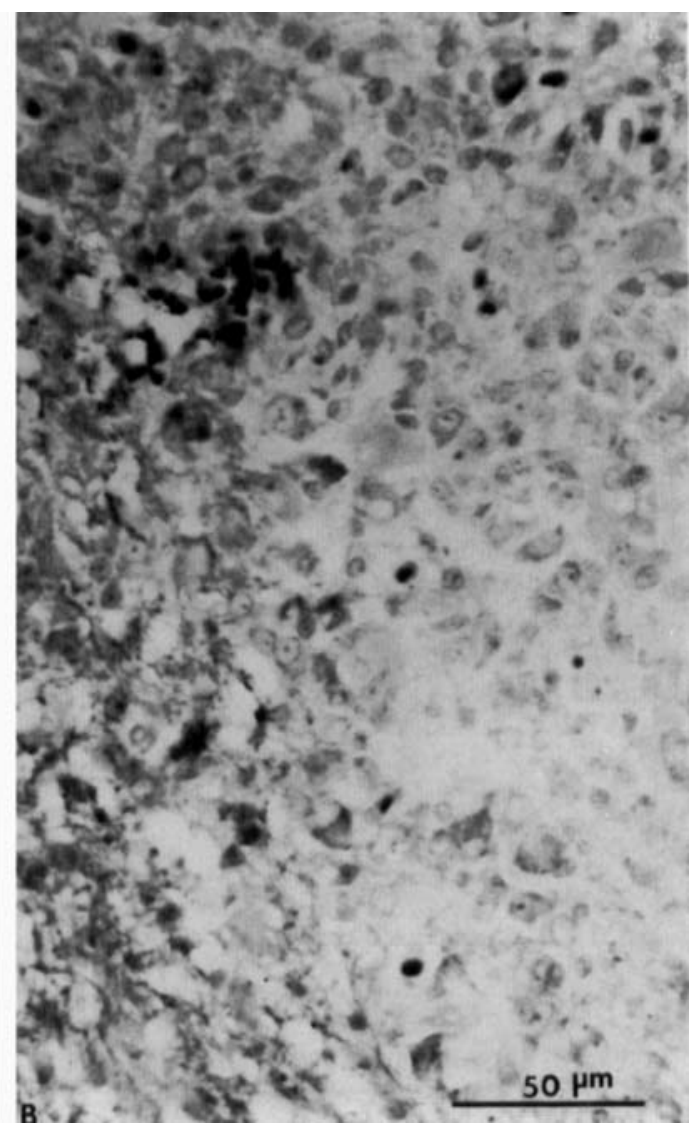

marked by asterisk. The demyelinated area contained numerous mononuclear cells and hypertrophied astrocytes which could be seen by GFAP immunostain (not shown).

increasing time the amounts of cholesterol ester formed were variable with the highest amount produced from serum from animals 26-27 days post immunization ( $32.7 \%$ of the cholesterol esterified). Two separate pools of sera from 32-35 day animals showed opsonizing activity differing substantially from each other (discussed below). At every time point from 10 days after immunization the amount of cholesterol ester produced from the sera was significantly higher than that from the FAC serum, $(\boldsymbol{P}<0.05)$. All values including the FAC control were significantly higher than that for untreated myelin $(P<0.01)$.

Variable amounts of cholesterol ester produced from serum collected at any one point were regularly seen even though each aliquot was taken from a serum pool from at least two animals, and several series of EAE animals were used. The activity of the macrophages differed greatly from one preparation to another, and this was probably the main source of the high standard errors (Fig. 4).

In one series of animals IgG was prepared from the 
A.

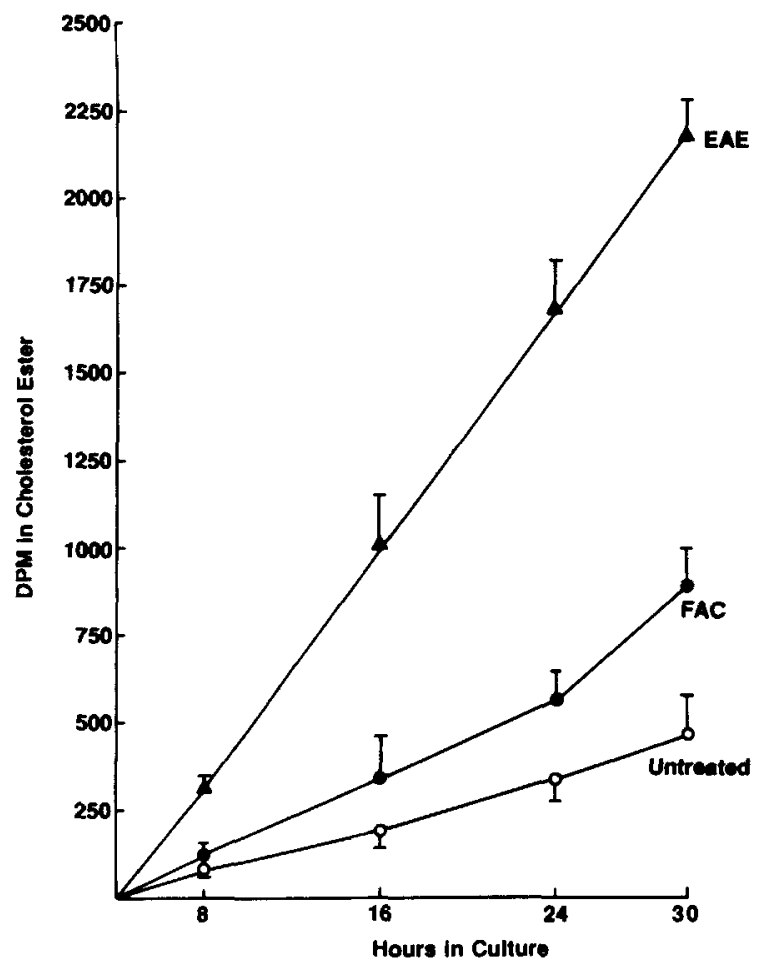

Fig. 3. Time course of production of radioactive cholesterol ester (A) and triglyceride (B) by macrophages during $30 \mathrm{hr}$ in culture. Each culture dish contained about $1.3 \times 10^{6}$ cells cocultured with preopsonized or untreated myelin $(0.1 \mathrm{mg}$ myelin protein) containing about $30,000 \mathrm{dpm}$. Lipids were pre-

sera using an affinity column (Protein G). When the IgG was properly corrected for losses during the preparative procedure, equivalent opsonizing activity to that of the parent serum was obtained (data not shown). All of the opsonizing activity, therefore, appears to be due to IgG, and complement does not seem to be involved. Our earlier findings that IgG did not account for all of the opsonizing activity in EAE serum (Smith and DeJong, 1987) was probably due to incomplete recovery of $\operatorname{lgG}$ from the Protein A affinity column which does not bind rat serum as well as Protein G.

\section{Serum Analysis}

One series of sera obtained from the EAE animals was analyzed by immunoblots. Immunostaining of MBP was seen from serum taken as early as 8 days after immunization, and then at 12 days the PLP and DM-20 band became evident (Fig. 5). These bands, especially the MBP, increased in intensity and remained prominently stained up to day 72 after immunization, while PLP which was prominent at 27 days gradually faded, as did cyclic nucleotide phosphohydrolase. A number of

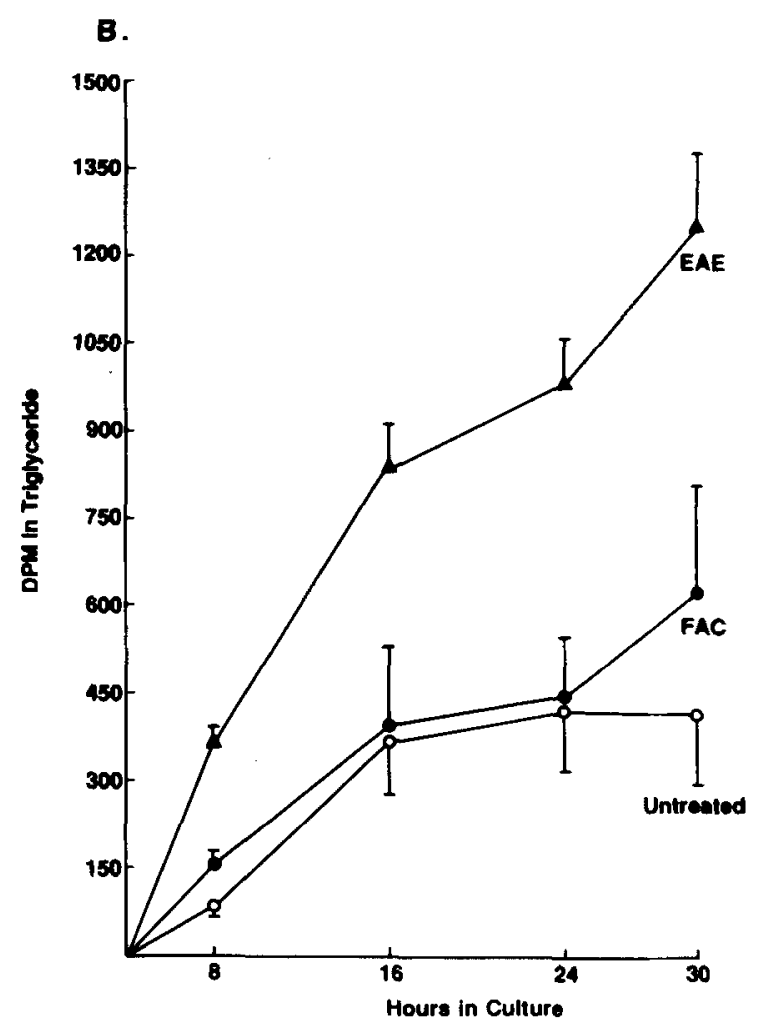

pared from the total culture + medium and the lipids were separated by thin layer chromatography. Each bar represents the average of results of three different experiments. Bars represent \pm S.E.M. EAE, experimental allergic encephalomyelitis serum; FAC, Freund's adjuvant control serum.

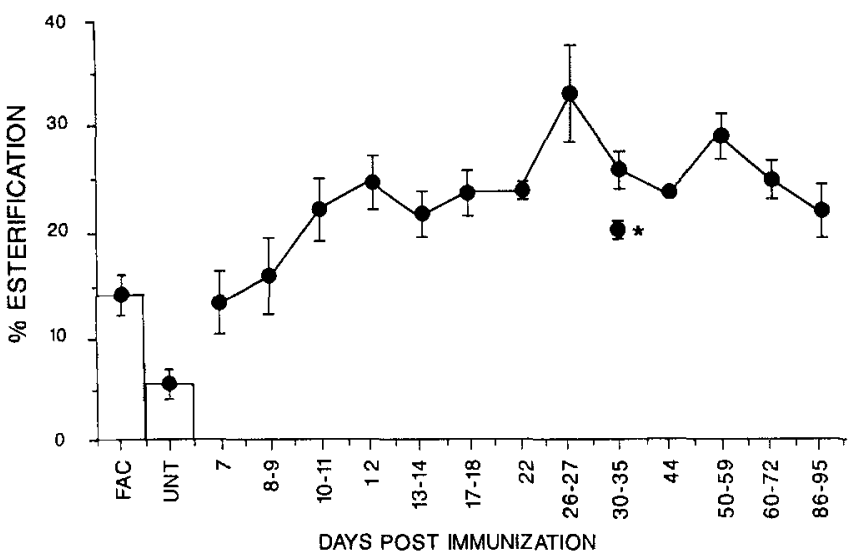

Fig. 4. Percent of cholesterol esterified in macrophage cultures incubated with $\left[{ }^{[4} \mathrm{C}\right]$-labeled myelin opsonized with serum from rats at different times after immunization. Incubation time was $30 \mathrm{hr}$. Point marked with asterisk represents culture containing myelin preopsonized with serum showing very little antibody as discussed in text. Each point represents experiments from 3-6 different serum pools. FAC, Freund's adjuvant control serum; UNT, untreated myelin. Bars represent \pm S.E.M. 


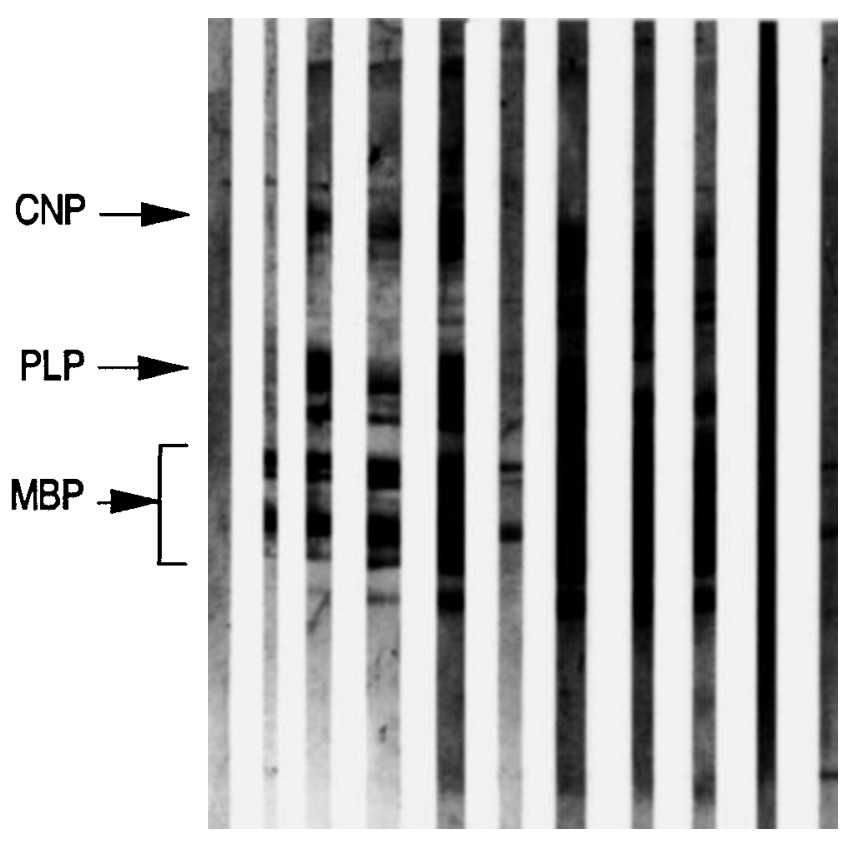

$\begin{array}{lllllllllll}1 & 2 & 3 & 4 & 5 & 6 & 7 & 8 & 9 & 10 & 11\end{array}$

Fig. 5. Immunoblots of a set of sera taken from rats at different times after immunization with whole myelin. Each serum sample is a pool from two identically treated rats. All animals showed severe clinical signs of EAE. Lane 1, EAE, day 7 post-immunization; lane 2, 10 days; lane 3, 12 days; lane 4, 18 days; lane 5, 27 days; lane 6, 32 days (see Results); lane 7, 52 days; lane 8, 59 days; lane 9, 72 days; lane 10, Freund's adjuvant control, 32 days, lane 11: Freund's adjuvant control, 66 days.

other bands appeared which were not identified. A lighter stain was seen with the serum from day 32 animals, corresponding to the low opsonizing value obtained from that serum (Fig. 4), although other sera from 30-35 day animals showed much heavier immunostaining (not shown here). Slight banding of the MBP was often evident in late sera from FAC animals, but these sera did not show increased opsonizing activity. Immunostaining of GC-dipped strips were negative in all rat sera tested, in contrast to earlier findings that serum from rabbits immunized with whole myelin stained GC strips prominently (Trotter et al., 1986). The increased immunostaining with time after immunization corresponded approximately to the opsonizing activity of the EAE sera. Where immunostaining was faint, as with the 32 days serum, less cholesterol esterification occurred.

$A$ relative measurement of the antibody titer to MBP and to PLP was obtained by the ELISA technique for two different serum series. The MBP measurements showed a steep rise in the relative amounts of antibody after seven days post immunization to reach final peaks at 35 and 37 days and then some decrease was noted (Fig. 6). PLP analyses from the same series displayed somewhat different courses with the second series showing an increase at day 12 and then subsequent sera were less active. Both, however, reached their maximum at 35-37 days, similar to the antibody titer for MBP (Fig. 7). All sera from Freund's adjuvant controls were negative for both MBP and PLP even though later FAC sera often showed faint immunostaining of myelin basic protein bands (Fig. 5). ELISA analyses for anti-GC were negative.

\section{DISCUSSION}

Previous work in this laboratory has demonstrated opsonizing activity of rabbit antiserum to PNS myelin, CNS myelin, myelin basic protein, and galactocerebroside as measured by esterification of CNS or PNS myelin cholesterol by macrophages. Antisera to $P_{0}$, PLP, and myelin-associated glycoprotein (MAG) did not promote myelin phagocytosis in our system (Trotter et al., 1986; Smith and DeJong, 1987; Smith et al., 1990). We show here that sera from rats that subsequently develop EAE after immunization with CNS myelin also opsonize CNS myelin. Different batches of sera from the same day postimmunization varied in activity and did not always correlate with clinical symptoms. A few animals with high antibody titers did not show clinical symptoms, while conversely occasional sera from animals with clinical symptoms showed low titers and opsonization activity. This lack of correlation may have been related to the location of the lesions. In general, the opsonizing activity correlated with the antibody amounts as seen both on Western blots, and in the case of MBP and PLP, with their relative quantitation by microtiter immunoassay.

It is less clear which antibody may be most effective for promotion of in vitro myelin phagocytosis and degradation by macrophages. Although MBP and GC antibodies are effective in stimulating myelin phagocytosis, no antibody to GC could be detected in the EAE rats. PLP antibodies were present in high amounts in the EAE animal, but we have not been able to show any effect of anti-PLP on myelin phagocytosis in vitro (Trotter et al., 1986). We have previously shown that serum from rats with EAE as a result of immunization with either guinea pig MBP or with whole myelin promoted myelin phagocytosis in vitro equally well (Smith and DeJong, 1987). Thus MBP antibody appears to be the most likely candidate for myelin opsonization. Other antigen possibilities, however, include cyclic nucleotide phosphohydrolase and the myelin oligodendrocyte glycoprotein (MOG) described by Linington and Lassman (1987), neither of which have been tested in our in vitro macrophage system. Furthermore, a number of other un- 


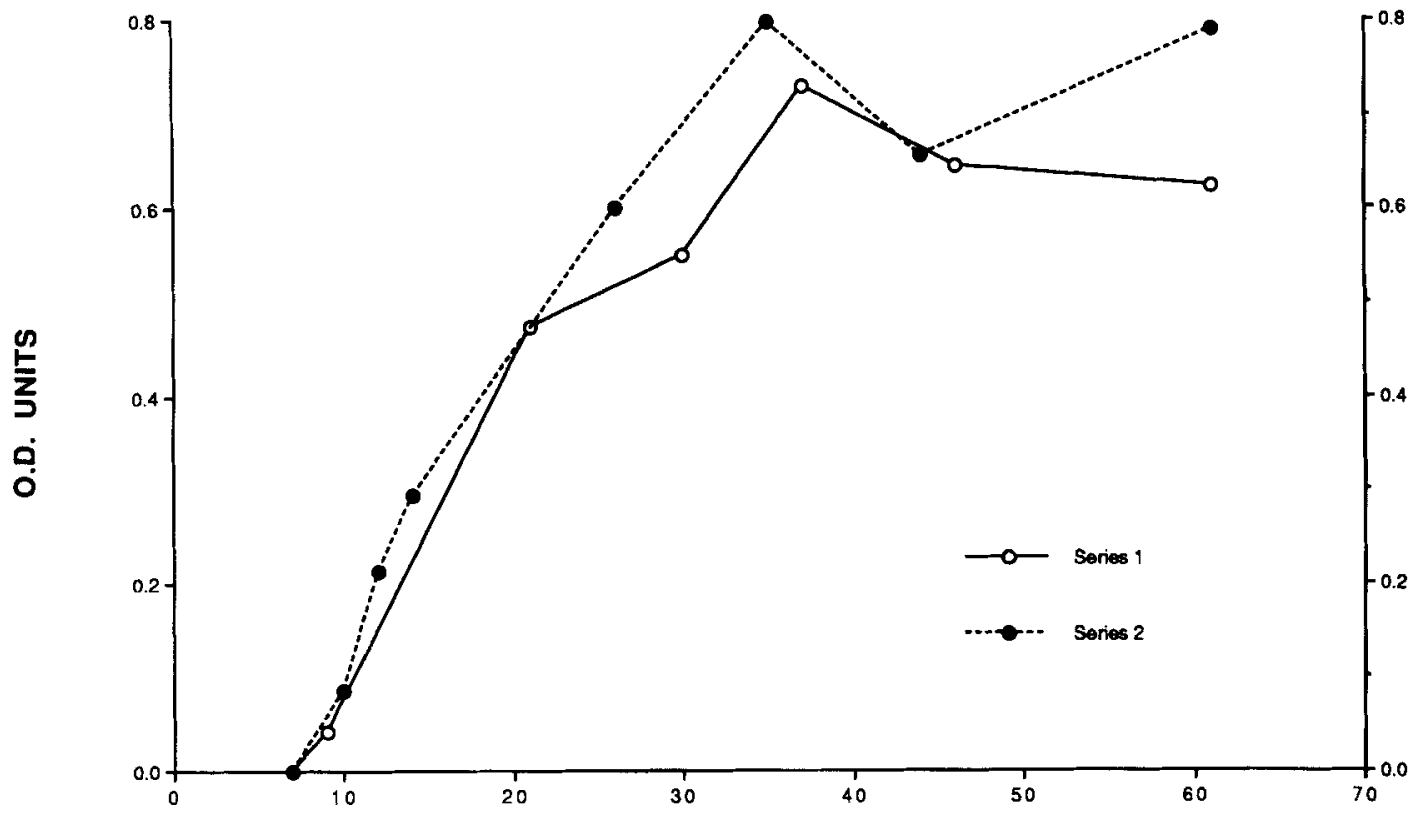

DAYS POST INJECTION

Fig. 6. Relative myelin basic protein antibody titers from two different series of sera from EAE rats at different times after immunization with purified myelin. Each serum sample is a pool from two identically treated rats. A microtiter plate was coated with myelin basic protein, and test sera were suitably

known myelin protein bands immunostained with the EAE serum (Fig. 5), indicating other antibody candidates.

Whether the opsonization activity of the sera promoting myelin phagocytosis in vitro is related to the demyelination seen in vivo is still uncertain. Although EAE has been established as a $T$ cell-mediated disease for many years, there is evidence that humoral factors are necessary for myelin pathology. In addition to a role in opsonization, antibody to a specific 14-residue peptide has been shown to be necessary for development of $T$ cells into an effector T cell-subset which leads to demyelination (Hashim and Day, 1988). Lewis rats with EAE do not usually show as large demyelinative lesions as are seen in other species, particularly those species developing a chronic relapsing disease (Raine et al., 1974). Nevertheless, demyelinated areas were observed frequently in our myelin-immunized animals. These lesions with characteristic discontinuities in luxol fast blue staining fibers were seen long after clinical recovery of the animal. Experiments in other species have implicated GC as a causal agent in demyelination. Thus Raine et al. (1981) reported that Hartley guinea pigs immunized with MBP alone developed severe EAE without demyelination, diluted using alkaline phosphatase for visualization as described under Materials and Methods. Optical density readings were analyzed with a microplate reader. Readings shown here were taken at a 1:400 serum dilution $20 \mathrm{~min}$ after addition of substrate.

while immunization with MBP + GC induced EAE with demyelination. The failure of Lewis rats to raise antibody against GC may be correlated to the relatively small amount of demyelination observed in this strain.

A number of investigations have demonstrated breakdown of the blood brain barrier at the time of onset of EAE in various species (e.g., Cutler et al., 1967; Hirano et al., 1970; and Juhler et al., 1984). While all have agreed that increased vascular permeability occurs just prior to or in early phases of EAE, the permeability at later stages is less well established, although Juhler et al. (1984) concluded that the permeability to sucrose had returned to normal by 21 days in the Lewis rat. The increased permeability at the time of acute inflammation would be expected to allow the entrance of peripheral blood IgG into the CNS parenchyma, thus allowing binding to the myelin sheath and effecting an in vivo opsonization. Infiltrating B cells may remain within CNS lesions after repair of the blood brain barrier, thus providing a localized supply of IgG for a longer period, and promoting growth of demyelinated areas. Furthermore the appearance of new lesions occurring after clinical recovery of the animal may also result in localized permeability to myelin-specific immunoglobulins. It has 


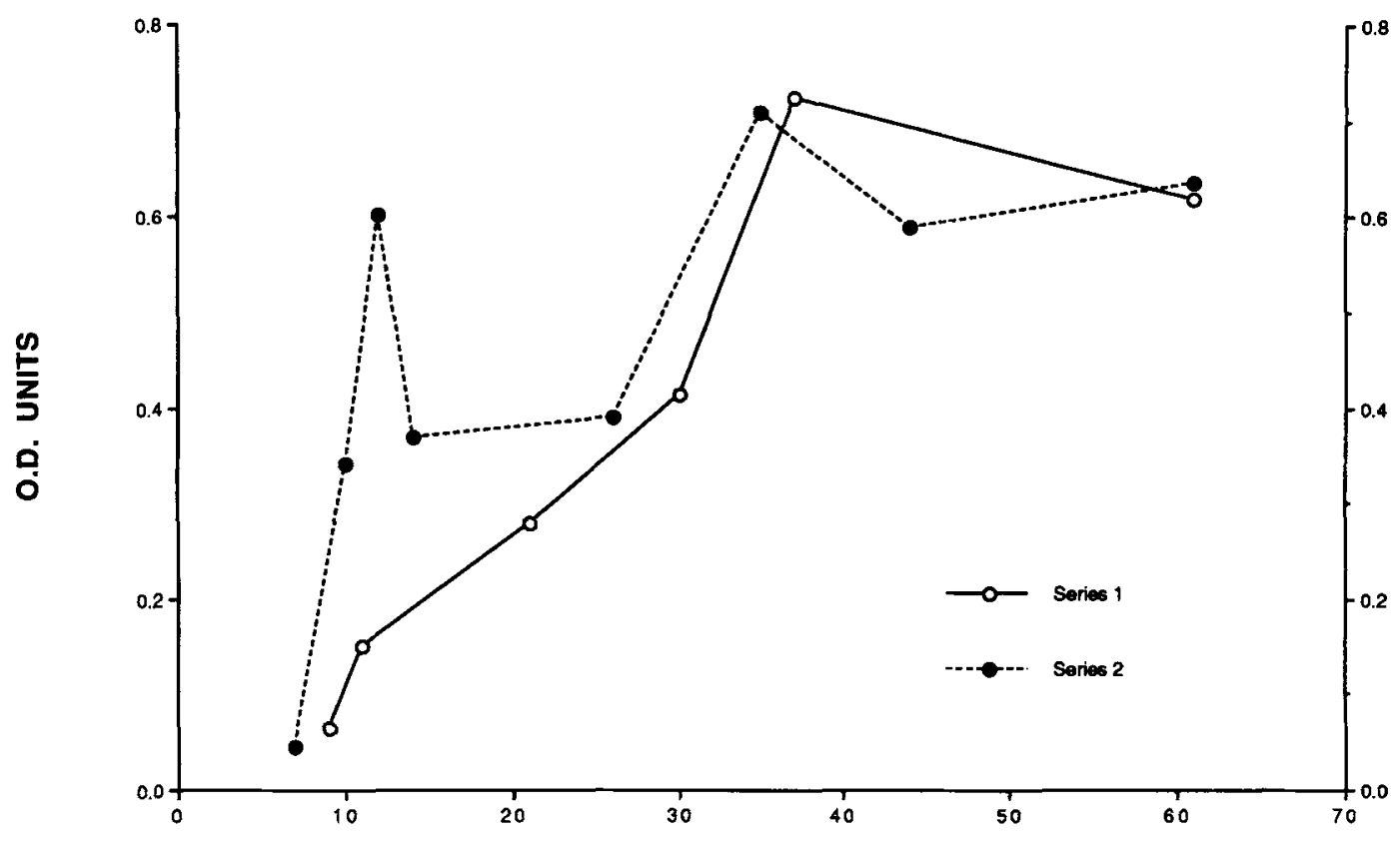

DAYS POST INJECTION

Fig. 7. Relative proteolipid protein antibody titers from two different series of sera from rats at different times after immunization with purified myelin. Procedures were similar to

been known for many years that EAE can be passively transferred by lymph node cells, but not by serum from EAE animals (Paterson, 1960). Nevertheless, antibodies, when given access to myelin through the blood-brain barrier may initiate or enhance the phagocytic response by peripheral or resident macrophages.

Some inconsistencies, on the other hand, speak against relating antibody effects in vitro with demyelination in vivo. While anti-PLP serum did not promote myelin degradation by macrophages in vitro (Trotter et al., 1986), extensive demyelination has been observed in rats with EAE as a result of PLP immunization (Yamamura et al., 1986). Less than half the animals showed clinical signs, however, with an onset much later than that seen with myelin basic protein ( 27 days compared to 11 days). The later onset of the PLP disease may possibly be related to the new lesions developing at later times observed in our whole myelin-immunized rats. Other investigators have shown a lack of correlation between antibody and demyelination. Thus Whitham et al. (1988) were not able to detect antibodies in mice with passively transferred chronic relapsing EAE, although extensive subpial demyelination was demonstrated. Similarly, Jones et al. (1990) obtained acute demyelinating EAE in Buffalo rats by the injection of MBP-specific T cell lines in the absence of antibody. those for Figure 6 except that PLP $(10 \mu \mathrm{g} / \mathrm{ml})$ coated the plate. Serum dilution for the above readings was $1: 400$, and readings were taken $30 \mathrm{~min}$ after addition of substrate.

Thus, while antibody may not be required for demyelination under special circumstances, the presence of antimyelin antibody could greatly exacerbate myelin destruction by phagocytosis within the CNS. Several alternative mechanisms for myelin destruction may be operative, of which an opsonization function for anti-myelin antibodies is a likely probability.

\section{ACKNOWLEDGMENTS}

The authors are grateful to Roxane Brown and Paul Somera for excellent technical assistance. We thank Dr. Marjorie Lees for a gift of proteolipid protein and advice on the ELISA procedure. This work was supported by the Department of Veterans Affairs, by grant number NS-02785 (Javits Neurosciences Award Grant) from the $\mathrm{NIH}$, and by the Multiple Sclerosis Society.

\section{REFERENCES}

Bottenstein JE, Sato GH (1979) Growth of a rat neuroblastoma line in serum-free supplemented medium. Proc Natl Acad Sci USA 76:514-517.

Cutler RWP, Lorenzo AV, Barlow CF (1967): Brain vascular permeability to $\mathbf{I}^{125}$ gamma globulin and leukocytes in allergic encephalomyelitis. J Neuropathol Exp Neurol 26:558-571.

Epstein LG, Prineas JW, Raine CS (1983): Attachment of myelin to 
coated pits on macrophages in experimental allergic encephalomyelitis. J Neurol Sci 61:341-348.

Goldenberg PZ, Kwon EE, Benjamins JA, Whitaker JN, Quarles RH, Prineas JW (1989): Opsonization of normal myelin by antimyelin antibodies and normal serum. J Neuroimmunol 23:157166.

Hashim GA, Day ED (1988): Role of antibodies in T cell-mediated experimental allergic encephalomyelitis. $J$ Neurosci Res 21: $1-5$.

Hirano A, Dembitzer HM, Becker NH, Levine S, Zimmerman HM (1970): Fine structural alterations of the blood-brain barrier in experimental allergic encephalomyelitis. J Neuropathol Exp Neurol 29:432-440.

Ichioka T, Uobe K-i, Stoskopf M, Kishimoto Y, Tennekoon G, Tourtellotte WW (1988): Anti-galactocerebroside antibodies in human cerebrospinal fluids determined by enzyme-linked immunosorbent assay (ELISA). Neurochem Res 13:203-207.

Johnson AB, Raine CS, Bornstein MB (1979): Experimental allergic encephalomyelitis. Serum immunoglobulin binds to myelin and oligodendrocytes in cultured tissue. Ultrastructural-immunoperoxidase observations. Lab Invest 40:568-575.

Jones RE, Bourdette DN, Offner H, Vandenbark AA (1990): Myelin basic protein-specific $\mathrm{T}$ cells induce demyelinating experimental allergic encephalomyelitis in Buffalo rats. J Neuroimmunol 30:61-69.

Juhler M, Barry DI, Offner H, Konat G, Klinden L, Paulson OB (1984): Blood-brain and blood-spinal cord barrier permeability during the course of experimental allergic encephalomyelitis in the rat. Brain Res 302:347-355.

Lampert P (1967): Electron microscopic studies on ordinary and hyperacute experimental allergic encephalomyelitis. Acta Neuropathol 9:99-126.

Laemmli UK (1970): Cleavage of structural proteins during the assembly of the head of bacteriophage T4. Nature 227:680-685.

Linington C, Lassman H (1987): Antibody response in chronic relapsing experimental allergic encephalomyelitis: Correlation of serum demyelinating activity and the antibody titre to the myelin/ oligodendrocyte glycoprotein (MOG). J Neuroimmunol 17:6169.
Macklin WB, Lees MB (1982): Solid-phase immunoassays for quantitation of antibody to bovine white matter proteolipid protein. J Neurochem 38:348-355.

Paterson PY (1960): Transfer of allergic encephalomyelitis in rats by means of lymph node cells. I Exp Med 111:119-136.

Prineas JW, Graham JS (1981): Multiple sclerosis: Capping of surface immunoglobulin $\mathrm{G}$ on macrophages engaged in myelin break. down. Ann Neurol 10:149-158.

Raine CS (1984): Analysis of autoimmune demyelination: Its impact upon multiple sclerosis. Lab Invest 50:608-635.

Raine CS, Snyder DH, Valsamis MP, Stone SH (1974): Chronic experimental allergic encephalomyelitis in inbred guinea pigs: An ultrastructural study. Lab Invest 31:369-380.

Raine CS, Traugott U, Farooq M, Bornstein MB, Norton WT (1981): Augmentation of immune-mediated demyelination by lipid haptens. Lab Invest 45:174-182.

Smith ME (1976): A lymph node neutral proteinase acting on myelin basic protein. J Neurochem 27:1077-1082.

Smith ME, DeJong LJ (1987); Antibody to myelin constituents: A possible factor in induction of cell-mediated demyelination. Neurochem Res 12:167-172.

Smith ME, Sadler RH, Dyer C, Benjamins JA, Yu ACH (1990): Phagocytosis of peripheral nerve myelin in vitro. Effect of antibody. J Neurosci Res 27:298-306.

Towbin H, Staehlin T, Gordon J (1979): Electrophoretic transfer of proteins from polyacrylamide gels to nitrocellulose sheets: Procedures and some applications. Proc Natl Acad Sci USA 76: $4350-4354$.

Trotter J, DeJong LA, Smith ME (1986): Opsonization with antimy elin antibody increases the uptake and intracellular metabolism. of myelin in inflammatory macrophages. J Neurochem 47 : $779-789$.

Whitham RH, Nilaver G, Bourdette DN, Seil FJ (1988): Serum antimyelin antibodies in chronic relapsing experimental allergic encephalomyelitis. J Neuroimmunol 18:155-170.

Yamamura $T$, Namikawa $T$, Endoh $M$, Kunishita $T$ and Tabira $T$ (1986): Experimental allergic encephalomyelitis induced by proteolipid apoprotein in Lewis rats. J. Neuroimmunol 12: $143-153$. 